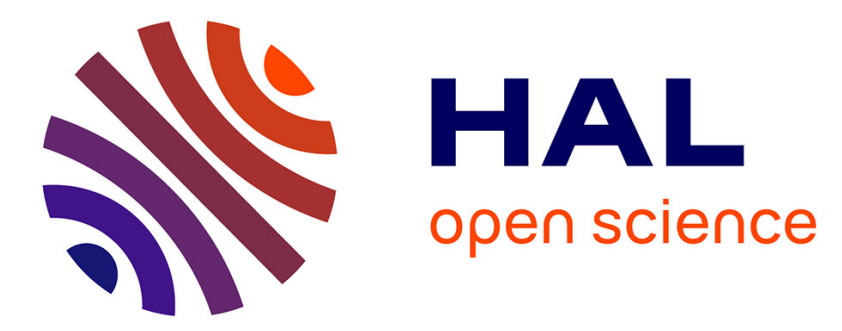

\title{
Tribological and corrosion experiments of graphite ring against Ti-6Al-4V disk: Influence of electrochemical and mechanical parameters
}

\author{
Ingrid Serre, Rachel Marie Pradeilles-Duval, N. Celati
}

\section{- To cite this version:}

Ingrid Serre, Rachel Marie Pradeilles-Duval, N. Celati. Tribological and corrosion experiments of graphite ring against Ti-6Al-4V disk: Influence of electrochemical and mechanical parameters. Wear, 2006, 260, pp.1129-1135. 10.1016/j.wear.2005.07.007 . hal-00111462

\author{
HAL Id: hal-00111462 \\ https://hal.science/hal-00111462
}

Submitted on 24 Jul 2019

HAL is a multi-disciplinary open access archive for the deposit and dissemination of scientific research documents, whether they are published or not. The documents may come from teaching and research institutions in France or abroad, or from public or private research centers.
L'archive ouverte pluridisciplinaire HAL, est destinée au dépôt et à la diffusion de documents scientifiques de niveau recherche, publiés ou non, émanant des établissements d'enseignement et de recherche français ou étrangers, des laboratoires publics ou privés. 


\title{
Tribological and corrosion experiments of graphite ring against Ti-6Al-4V disk: Influence of electrochemical and mechanical parameters
}

\author{
I. Serre ${ }^{\mathrm{a}, \mathrm{b}, 1}$, R.M. Pradeilles-Duval ${ }^{\mathrm{b}, *}$, N. Celati ${ }^{\mathrm{a}}$ \\ a DGA/DCE/centre technique d'Arcueil, 16 bis av. Prieur de la Côte d'Or, F-94114 Arcueil Cedex, France \\ ${ }^{\mathrm{b}}$ Laboratoire de Mécanique des Solides, CNRS UMR 7649, Ecole Polytechnique, F-91128 Palaiseau, France
}

\begin{abstract}
Friction of two materials in artificial seawater induces severe degradations of both antagonists. In view of evaluating materials wear resistance, this investigation is devoted to the development of a new ring-on-disk tribocorrosimeter device. Its relevance to the study of wear due to plan/plan friction is analyzed comparing it to classical pin-on-disk experiments, with special emphasis on the influence of several factors: choice and respective position of both materials in contact, applied load, test duration.
\end{abstract}

Keywords: Tribocorrosion; Plan/plan contact experiments

\section{Introduction}

When used in a marine environment, planar contacts and ring-on-disk systems such as boat pumps or packing glands are expected to ensure their sealing capacity. The problem considered here consists in two rings in contact and in rotating with respect to each other. The friction phenomenon between the both rings induces a material wear, which can alter the waterproofing and the sealing capacity of the system. Tribocorrosion experiments can be used to analyze the mechanical and electrochemical wear modes, in view of the determination of the material wear laws, thanks to numerical simulation. Coupling between experimental data and numerical simulations can be involved to determine the system durability $[1,2]$.

Usually tribocorrosion experiments are carried out by using a pin-on-disk tribocorrosimeter with an alumina pin [3-5]. Alumina is chosen due to its neutral electrochemical properties:

\footnotetext{
* Corresponding author at: Direction de la Formation et de la Recherche, ENSTA, 32 Boulevard Victor, F-75739 Paris Cedex 15, France.

Fax: +33145525493.

E-mail address: rmpduval@1ms.polytechnique.fr (R.M. Pradeilles-Duval).

${ }^{1}$ Present address: Laboratoire de Métallurgie Physique et Génie des Matériaux, CNRS UMR 8517, Université de Lille, F-59655 Villeneuve d'Ascq, France.
}

thus, the electrochemical phenomena occurring at the surface of the other material can be more easily explained by the measured electrochemical current. Moreover, because of its higher mechanical properties, no loss of material or significant degradation is observed for the alumina pin. Then any variation of the contact geometry during the test can only derive from a loss of matter of the non-alumina disk. In addition, it is well known that the wear behavior depends on the contact geometry, and the time evolution of its configuration (steady-state or periodic contact) $[6,7]$. So, using systematically an alumina pin is restrictive. That is why a ring-on-disk tribocorrosion device electrochemically and mechanically instrumented was developed in order to study the wear behavior of two materials in contact.

The purpose of this paper is to analyze and to understand the influence of the electrochemical and mechanical parameters on tribocorrosion wear. The paper is organized as follows: we first describe and analyze the tribocorrosion experiments and then the studied materials: a graphite and a titanium alloy. In Section 3, we present the results and the influence of various parameters on friction coefficient and electrochemical parameters: respective configuration (ring or disk) of the materials, applied load, test duration and global geometry of the contact. Finally, suggestions are made on the test duration and on the contact conditions, in connection with the industrial case under study. 


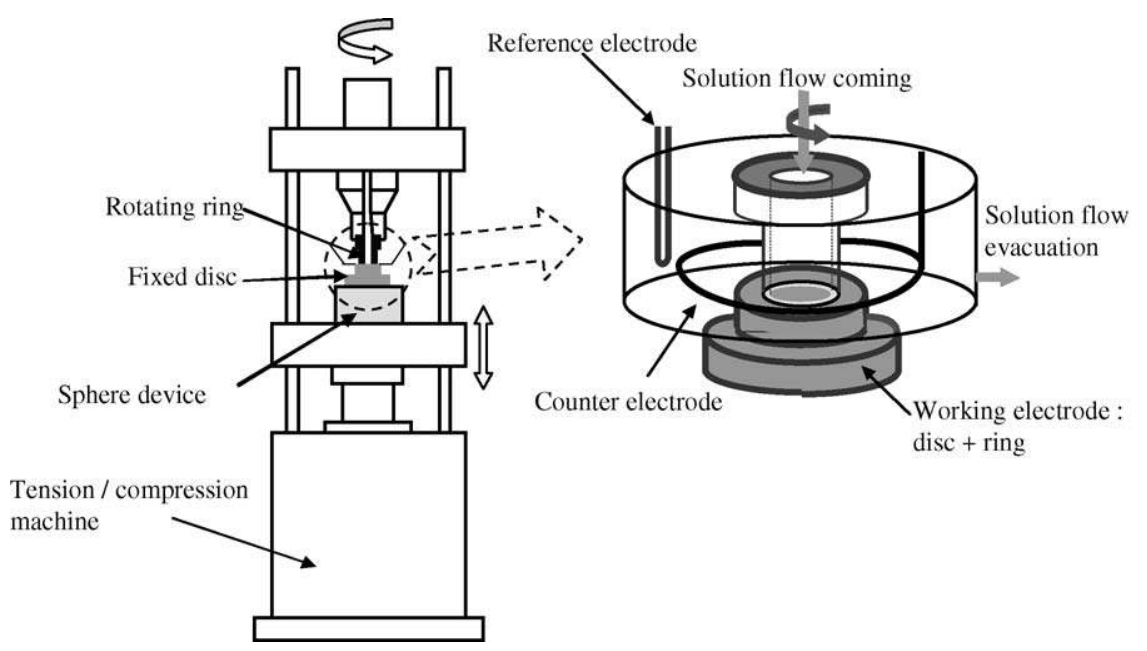

Fig. 1. The principle of the ring-on-disk tribometer.

\section{Experimental device}

\subsection{Description of the tribocorrosimeter}

The tribometer is a ring-on-disk tribocorrosimeter developed by a technical centre of the French Armament Procurement Agency ("centre technique d'Arcueil", CTA-DGA). The device consists in a fixed disk and a rotating ring (Fig. 1). A normal pressure applied by a servo-hydraulic tension/compression machine maintains the contact between the samples. An electrochemical cell is used to perform corrosion tests in artificial seawater under fixed electrochemical conditions. The ring has an average radius of $8 \mathrm{~mm}$ and the width of the contact zone is $3 \mathrm{~mm}$. In order to maintain a plan/plan contact with the ring, the fixed disk is assembled on a spherical kneecap.

All the experiments were performed at room temperature in artificial seawater, $(\mathrm{NaCl}$ solution to $30 \mathrm{~g} / \mathrm{l}$ buffered at $\mathrm{pH}$ 8 according to NFA 91411 standards). A three-electrode set-up (Figs. 1 and 2a)) was used to impose an electrochemical potential on the exposed surface of both samples and to measure the current. The given values of the electrochemical potential are referred to the $\mathrm{Ag} / \mathrm{AgCl}$ saturated in $\mathrm{KCl}$ electrode. A circulation of the electrolyte was put in place (Fig. 1) for stability of the artificial seawater characteristics during the tests.

\subsection{Experimental outputs}

\subsubsection{The friction coefficient}

Numerical boundary element method (BEM) simulations [8] have been involved with the materials presented hereafter. The distribution of the contact pressure is as expected not uniform. It is higher near the two edges of the contact zone. This can explain that the loss of matter is likely to be initiated under these edges. The same qualitative observation was made by Water et al. [9] from ring-on-disk tribocorrosion experiments.

The measured friction coefficient $\mu(t)$ is a global Coulomb friction coefficient, i.e., the ratio between the actual tangential force and the actual applied normal force. Moreover, the radial tangential force can be neglected with respect to the orthoradial tangential one. As defined by Fig. 3, the average value on the track of the radial tangential stress $\sigma_{\mathrm{rz}}$ is about $0.01 \mathrm{MPa}$ while the orthoradial tangential stress $\sigma_{\theta \mathrm{z}}$ and the normal stress $\sigma_{\mathrm{zz}}$ are

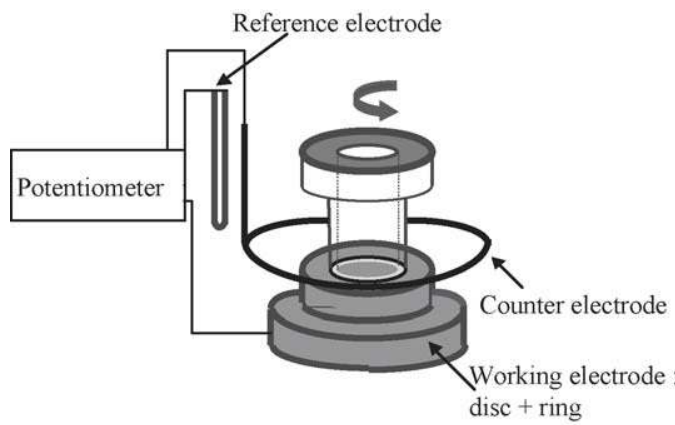

Standard electric circuil

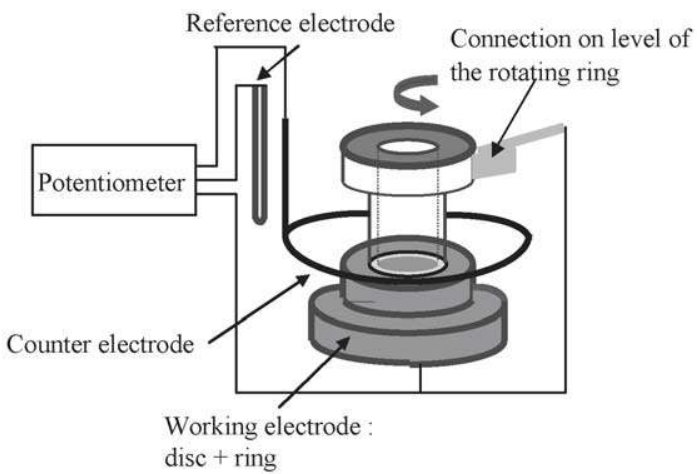

the connection with the circuit electric for the ring and for the disk

(B)

Fig. 2. Electrochemical set-up (electric circuit). 


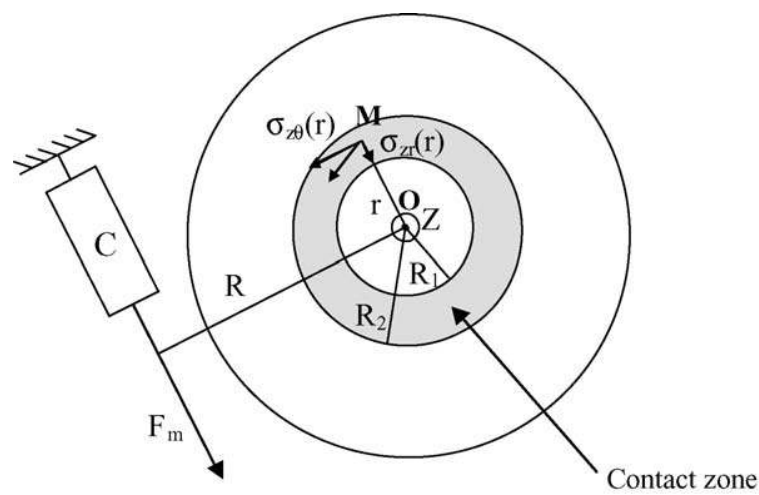

Fig. 3. Measure of the friction forces.

0.75 and $5 \mathrm{MPa}$, respectively. So, in the following, the measured global Coulomb friction coefficient $\mu(t)$ is given by the ratio of the mean orthoradial tangential force $\left(F_{\mathrm{t}}\right)$ and the applied normal force $\left(F_{\mathrm{n}}\right)$ :

$F_{\mathrm{t}}=2 \pi \int_{R_{1}}^{R_{2}} \sigma_{\theta \mathrm{z}} \mathrm{d} r$ and $F_{\mathrm{n}}=2 \pi \int_{R_{1}}^{R_{2}} \sigma_{\mathrm{zz}} \mathrm{d} r$

A force sensor $\mathrm{C}$ (Fig. 3) was used to block the disk rotation and to measure a tangential force $\left(F_{\mathrm{m}}\right)$. Equilibrium moment in the vertical $z$-direction induces a relation between $F_{\mathrm{m}}$ and $F_{\mathrm{t}}$ :

$F_{\mathrm{t}}=\frac{3}{2} \frac{\left(R_{2}^{2}-R_{1}^{2}\right)}{\left(R_{2}^{3}-R_{1}^{3}\right)} R F_{\mathrm{m}}$

where $R_{1}, R_{2}$ and $R$ are, respectively, the internal, external radii of the track and the force sensor radius measured from the apparatus axis (Fig. 3). In the previous, the dependence of the $z$ moment versus the radial position is taken into account. Finally, it leads to the coefficient:

$\mu(t)=\frac{F_{\mathrm{t}}(t)}{F_{\mathrm{n}}(t)}$.

\subsubsection{Electrochemical measurements}

As mentioned above, the choice of the materials, motivated by a given structural application, is such that both of them are electrochemically active. Several questions show up: is there a galvanic coupling between the two materials? Do the samples in contact have the same potential during the tests? What is the signification of the measured current during the tribocorrosion tests?

First, the risk of a galvanic coupling depends on the nature of the materials but also on the ratio of both areas in contact with the electrolyte. For our experiments, the area of the ring in contact with the electrolyte is approximately four times larger than the area of the disk in contact with the artificial seawater. But, due to the respective positions of the ring and of the counter electrode, a part of the surface of the ring (especially the inner one) is electrochemically masked. It follows directly from these remarks that the risk of the galvanic coupling cannot be followed from separate electrochemical studies on each material. Consequently, the two configurations (ring in one material, disk in the other and vice versa) had to be studied (see Section 3.1), in order

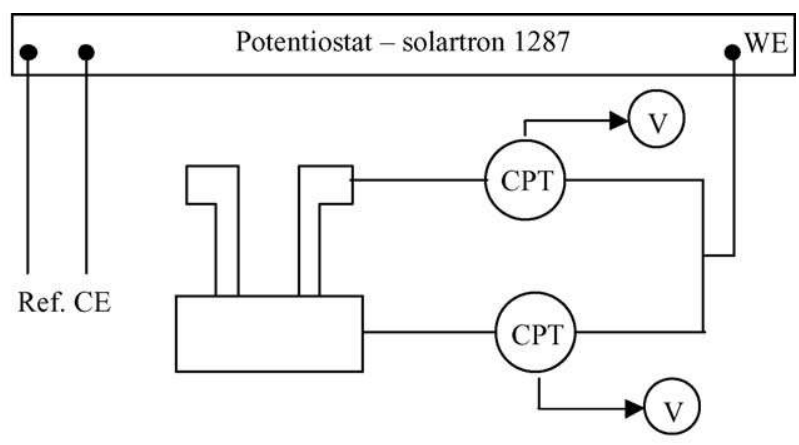

CPT : current / potential converter, CE : counter electrode Ref. : Reference electrode, WE : working electrode

Fig. 4. Electrochemical set-up with current/potential converters (electric circuit).

to evaluate the influence of the materials location on galvanic coupling.

By using the standard electrochemical set-up reported in Fig. 2a, either the potential is fixed and a current is measured or the free potential is measured. The working electrode is assumed to be constituted of the two samples and the connection between the working electrode and the electric circuit usually occurs on the disk. Nevertheless, due to the motion of the samples with respect to each other, a difference of the potential can exist between the disk and the ring. To check this point, we use the electrochemical set-up reported in Fig. 2b. A connection with the electric circuit is established for each sample to measure the difference of potential between the disk and the ring during free potential experiments. With the studied materials (graphite and titanium alloys), we measure a difference of potential equal to $5 \mathrm{mV}$.

Finally, when a potential is imposed, the measured current is the sum of the contribution of each material; the contribution of each material is unknown. To evaluate the respective contributions, some specific experiments are carried out with an electrochemical set-up based on the current/potential converters [10] (see Fig. 4). In Fig. 5, we see the electrochemical contributions of the both studied materials (Ti-6Al-4V and graphite) in two configurations: in contact without friction, and in con-

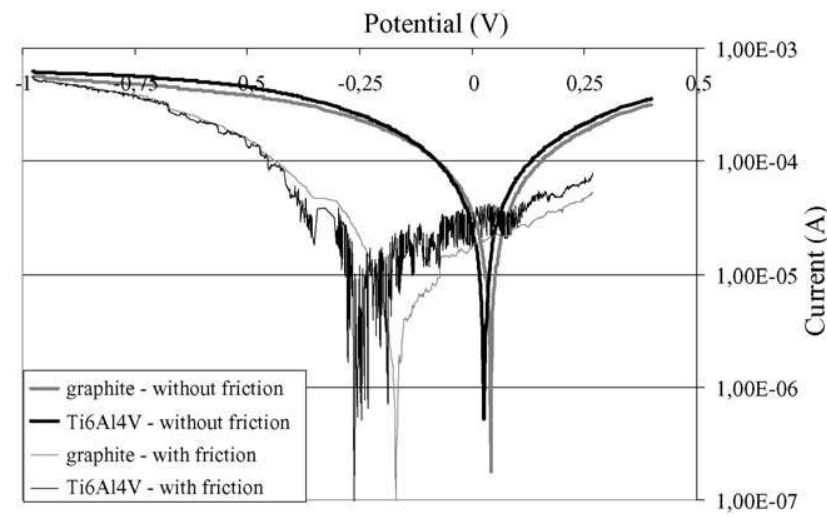

Fig. 5. Contributions of each material to the elecrochemical current: potentiodynamic polarisation curve during tribocorrosion experiments with and without friction (test conditions: see Section 3.3; applied load: $400 \mathrm{~N}$ ). 
tact with friction. The interpretation of the current is not easy because of the evolution of the surfaces of the samples due to the friction contact. But we observe the important decrease of the corrosion potential for the Ti-6Al-4V during friction. This phenomenon in connection with a wear of Ti-6Al-4V according to the applied potential during tribocorrosion experiments [11] is associated with depassivation/repassivation phenomena of the Ti-6Al-4V. So, this set-up is a help for the understanding of the electrochemical phenomena during tribocorrosion tests.

Because it is quite difficult to maintain the connection with the moving sample during 6- or 50-h experiment (set-up reported in Fig. 2b), in the following, unless specified, the standard electrochemical set-up of Fig. 2a is used, with the assumption of perfect contact.

\subsubsection{Wear measurement}

After each test, the total wear of the disk is evaluated by profilometry, and the height of the ring is measured before and after each test. This results in the evaluation of the total loss of matter for each sample. To determine the wear law from the comparison between the experimental results and the numerical simulations, the measured evolution of the samples wear rate is needed. That is why the displacement of the crosshead of the tensile machine is continuously measured. Since no evolution of the elastically deformation of the apparatus (ring, disk and system around the samples) has been observed during the experiment, the evolution of the measured displacement corresponds to the relative axial displacement between the disk and the ring. It provides useful informations about the wear rate evolution and the presence of wear debris in the contact zone as underlined in Section 3.3.

\section{Experimental results and discussion}

The average normal pressure between the two materials is controlled thanks to a servo-hydraulic machine. The pressure is time-independent and less than $10 \mathrm{MPa}$. The rotational speed of the ring is fixed and equal to $40 \mathrm{rpm}$, which corresponds to a mean linear velocity of $0.033 \mathrm{~m} / \mathrm{s}$. The experiments are $6 \mathrm{~h}$ long, unless specified otherwise.

\subsection{Studied materials}

One of the samples is cut from a cube of Hot Isostatically Pressed (HIP) sintered graphite. The material is elastic, brittle and isotropic [12]. The other sample is made of Ti-6Al-4V or of TiC-reinforced Ti-6Al-4V coating on a Ti-6Al-4V substrate. The TiC-reinforced Ti-6Al-4V coating width is about $2 \mathrm{~mm}$. Due to the low magnitude of the applied load, only the properties of the coating influence the mechanical response of the sample when coated. According to the loading conditions and the mechanical behavior of these titanium alloys, they may be assumed as elastic.

The electrochemical behavior is derived from the measurement of the free potential after 1-h experiment in artificial seawater (Table 1). The free potential of graphite is higher than the one of the titanium alloys. This result provides us with the elec-
Table 1

Free potential of the materials in artificial sea water (after $1 \mathrm{~h}$ )

\begin{tabular}{lc}
\hline Material & \multicolumn{1}{c}{ Free potential (mV) } \\
\hline Graphite & $95 \pm 50$ \\
Ti-6Al-4V & $-265 \pm 145$ \\
$10 \%$ TiC-reinforced Ti-6Al-4V & $-105 \pm 75$ \\
$15 \%$ TiC-reinforced Ti-6Al-4V & $-140 \pm 80$ \\
\hline
\end{tabular}

Table 2

Volume loss of graphite $\left(\mathrm{mm}^{3}\right)$ for the two configurations

\begin{tabular}{lll}
\hline Conditions of experiments & \multicolumn{2}{l}{ Geometry } \\
\cline { 2 - 3 } & Configuration 1 & Configuration 2 \\
\hline $\begin{array}{l}\text { Imposed potential of } \\
-1.010 \mathrm{~V}, \text { load } 400 \mathrm{~N}\end{array}$ & $4.5 \pm 0.8$ & $2.6 \pm 1.1$ \\
Open circuit, load $800 \mathrm{~N}$ & $2.5 \pm 1.9$ & $1.1 \pm 0.8$ \\
\hline
\end{tabular}

trochemical coupling through the corrosion of titanium alloys by graphite, as analyzed below.

\subsection{Influence of geometry}

To understand the influence of geometry, two configurations have been studied: configuration 1 refers to the case where the ring is made of graphite and the disk is made of Ti-6Al-4V, and configuration 2 to the reverse situation. No potential is imposed. The free potential of the working electrode is measured.

For both configurations, the same value of the friction coefficient is found: its average value is $0.16 \pm 0.04$ after $6 \mathrm{~h}$. The free potential of the two materials is about the same order for both configurations too: between -0.110 and $-0.125 \mathrm{~V}$. Ti-6Al-4V wear mainly corresponds to an increase of roughness in both configurations. The loss of graphite is more important in the configuration 1 (Table 2). The wear of the ring is almost uniform across the width of the contact zone. The height variations are less than $1 \mu \mathrm{m}$ for an average value of more than $10 \mu \mathrm{m}$. On the contrary, the wear of the graphite disk is not uniform: it is higher on the external edge of the contact zone (Fig. 6). These differences can be explained by the evolution of the contact geometry, which differs according to the configuration. This might be due, at least in part, to the evacuation of the graphite debris out of the friction zone. As shown in Fig. 7, in configuration 1 , the graphite debris can be ejected out of the contact area more easily than in configuration 2 where they are maintained inside the track. In [13], Stemp et al. observed comparable wear volume with a comparable wear volume a metal pin sliding on a ceramic disk and the reverse situation despite the different wear mechanisms. This work and our results raise up that the geometry of the samples, their respective configuration and the wear behavior are coupled.

In the following, configuration 1 only is considered.

\subsection{Influence of mechanical loading}

The average contact pressure is either 2.65 or $5.3 \mathrm{MPa}$, for an applied normal force of 400 and $800 \mathrm{~N}$, respectively. The influ- 


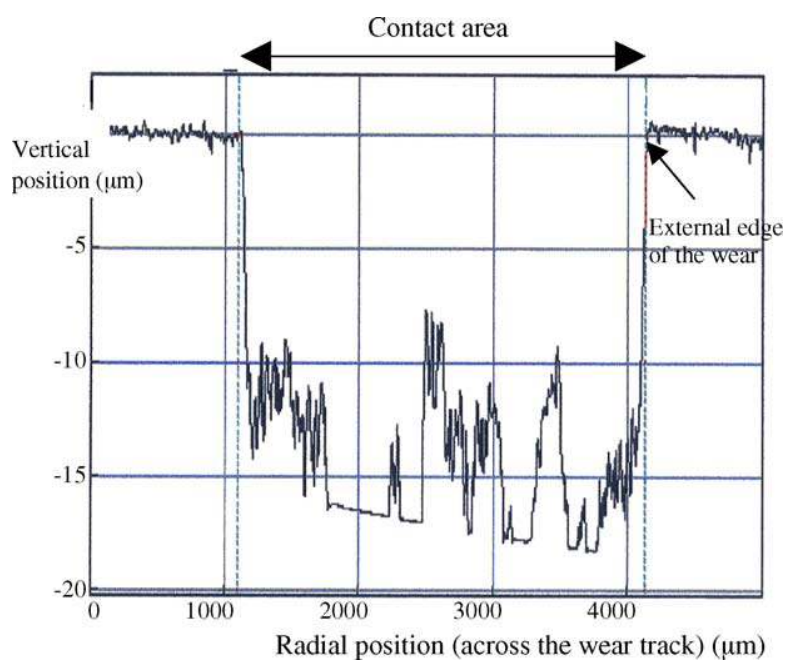

Fig. 6. Profilometry of the wear track for the graphite sample (free potential; applied load: $800 \mathrm{~N}$, without artificial sea water circulation).

ence of the applied load is studied for two imposed potentials: -1.010 and $0.140 \mathrm{~V}$. For the experiments with a potential equal to $-1.010 \mathrm{~V}$, there is no influence of the loading on the mean value of the friction coefficient and on the measured current was observed. But, with a potential equal to $0.140 \mathrm{~V}$, the larger the applied force $(400$ or $800 \mathrm{~N})$, the smaller the friction coefficient. In addition, the measured current is smaller with a normal force of 400 at $0.140 \mathrm{~V}$ and not at $-1.010 \mathrm{~V}$. As underlined in [14], the electrochemical current increases with the mechanical loading.

At the end of the experiment for $-1.010 \mathrm{~V}$, no loss of matter of $\mathrm{Ti}-6 \mathrm{Al}-4 \mathrm{~V}$ is measured (by profilometer). But an increase of roughness of the contact zone of $\mathrm{Ti}-6 \mathrm{Al}-4 \mathrm{~V}$ is observed. It is $0.2 \mu \mathrm{m}$ after a $400 \mathrm{~N}$ experiment and $0.4-0.5 \mu \mathrm{m}$ with an $800 \mathrm{~N}$ load. The disk is more damaged in these last cases. For experiments at $0.140 \mathrm{~V}$, a loss of matter from the Ti-6Al-4V disk is measured; it is $0.210 \pm 0.062 \mathrm{~mm}^{3}$ at $800 \mathrm{~N}$ compared to $0.103 \pm 0.052 \mathrm{~mm}^{3}$ at $400 \mathrm{~N}$. The difference is readily explained by the local depassivation/repassivation phenomena. It is more active under a larger load (Fig. 8).
Table 3

Reduction height $(\mu \mathrm{m})$ of the graphite ring: influence of load

\begin{tabular}{lll}
\hline Conditions of experiments & \multicolumn{2}{l}{ Applied normal load } \\
\cline { 2 - 3 } & $400 \mathrm{~N}$ & $800 \mathrm{~N}$ \\
\hline $\begin{array}{l}\text { Imposed potential of } \\
\quad 1.010 \mathrm{~V}, \text { without } \\
\text { circulation of artificial sea } \\
\quad \text { water }\end{array}$ & $28.0 \pm 5.0$ & $21.0 \pm 3.0$ \\
$\begin{array}{l}\text { Imposed potential of } 0.140 \mathrm{~V}, \\
\text { with circulation of artificial }\end{array}$ & $9.0 \pm 1.5$ & $16.5 \pm 4.0$ \\
$\quad$ sea water & & \\
\hline
\end{tabular}

For a potential of $-1.010 \mathrm{~V}$ and a normal force of $400 \mathrm{~N}$, the loss of the graphite matter is more important without circulation of artificial seawater (Table 3). In contrast, by coupling a circulation of artificial sea water and an anodic potential $(0.140 \mathrm{~V})$, opposite results are obtained (Table 3$)$. These variations are probably due to several factors such as the properties of the Ti-6Al-4V surface, which vary with the potential, the evacuation of the wear debris that depends on load and on the circulation of artificial seawater. For a given potential of $-1.010 \mathrm{~V}$, Fig. 9 gives the axial displacement of the crosshead of the tensile machine. The displacement results from the wear of the graphite ring and the third body. The Ti-6Al-4V disk does not suffer any loss of matter. For the experiments under $400 \mathrm{~N}$, this displacement does not evolve linearly in time but rather stepwise. The steps testify that wear debris are accumulated in the contact area (no axial displacement) before they are ejected out of the friction zone (stepwise evolution of the displacement). The contrast between a constant friction coefficient and an evolving axial displacement is associated to the existence of graphite transferred on the disk. Graphite/Ti-6Al-4V contact and graphite/graphite contact are simultaneously present in the track. At $800 \mathrm{~N}$, the displacement curve is smoother, except during the initial phase of the experiment. The higher local pressure is probably crucial for the destruction of debris and their ejection.

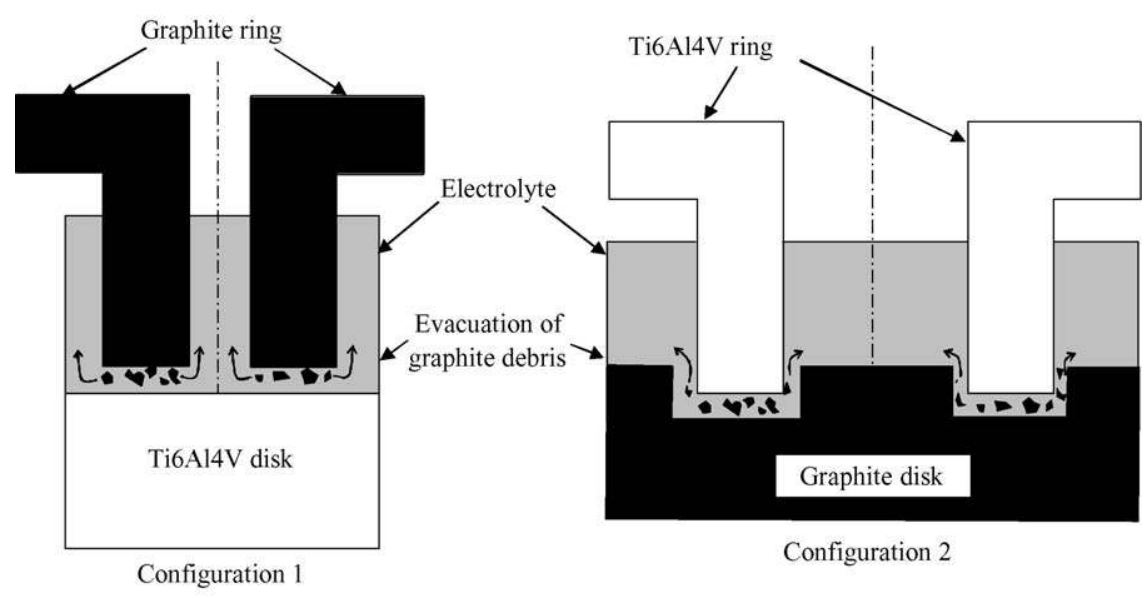

Fig. 7. Influence of the configuration on the evacuation of the graphite debris (emphasized scale). 

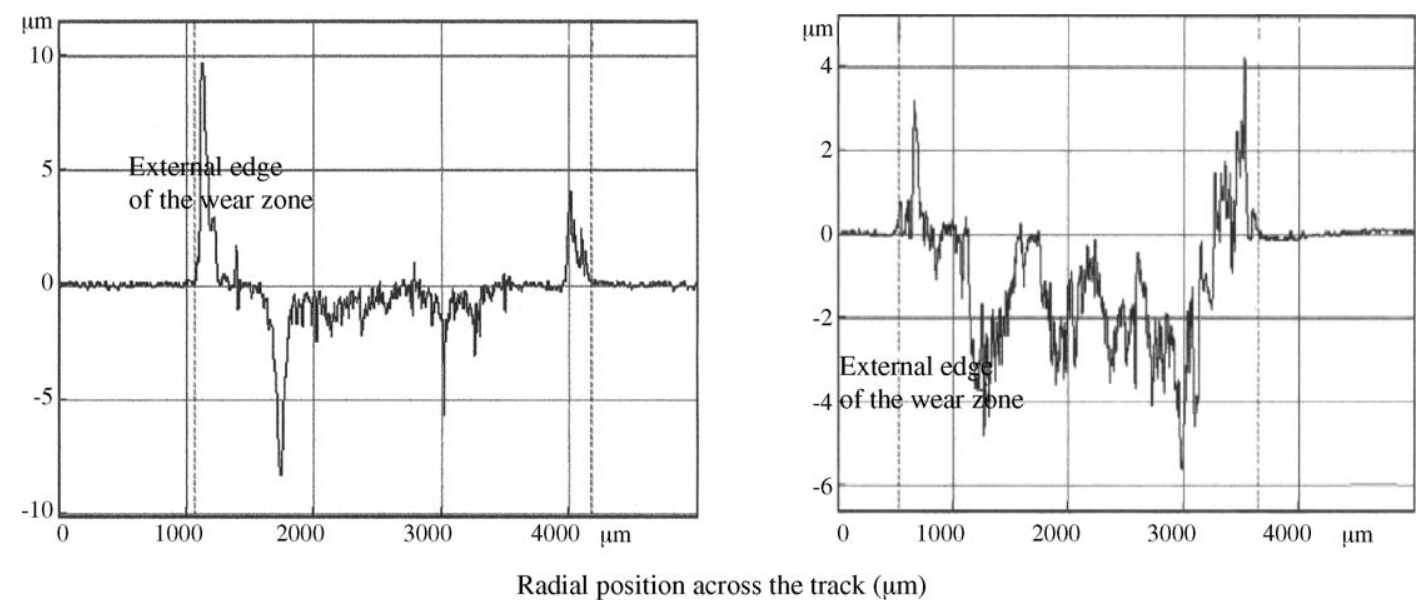

Applied load: $400 \mathrm{~N}$

Applied load : $800 \mathrm{~N}$

Fig. 8. Influence of the applied load. Profilometry of the wear track for the Ti-6Al-4V sample (applied potential: $0.140 \mathrm{~V}$, with artificial sea water circulation).

\subsection{Test duration}

The main goal of the longer experiments is to observe the time evolution of wear. The 50-h long experiments are carried out at a given potential equal to $-0.060 \mathrm{~V}$, which corresponds to the value of the industrial application (friction contact between graphite and titanium alloy during 10,000 h).

The comparison between 6-h and 50-h-experiments shows a more important roughness of the Ti-6Al-4V track for the longest tests. Furthermore, the corrosion products are observed not only near the edges of the friction zone as observed for 6-h experiment, but also in the middle of the wear track. This phenomenon is due to the time evolution of the local electrochemical potential and of the local properties of the electrolyte. The loss of the graphite ring corresponds to a height decrease equal to $20 \pm 2 \mu \mathrm{m}$ after $6 \mathrm{~h}$ and to $90 \pm 10 \mu \mathrm{m}$ after $50 \mathrm{~h}$. Assuming the wear rate obtained after 6-h experiments remains constant till $50 \mathrm{~h}$, the extrapolated loss of height would have been up to $165 \mu \mathrm{m}$ for 50 -h experiments, which is nearly twice the measured value. It suggests that the wear does not reach a steadystate regime after $6 \mathrm{~h}$. The lifetime cannot be extrapolated solely from the results of 6-h experiments. In order to validate this conclusion, some experiments have been performed in the same conditions with another couple of materials: graphite and $\mathrm{TiC}$ reinforced $\mathrm{Ti}-6 \mathrm{Al}-4 \mathrm{~V}$ coating on $\mathrm{Ti}-6 \mathrm{Al}-4 \mathrm{~V}$ substrate. The

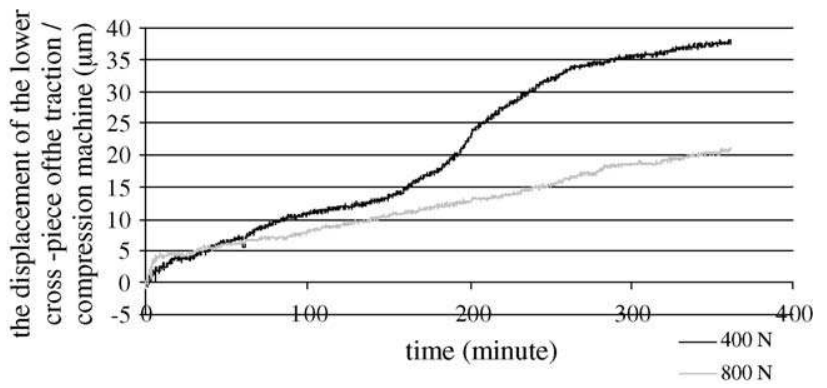

Fig. 9. Influence of load on the displacement of the lower crosshead of the tensile machine (applied potential: $-1.010 \mathrm{~V}$; without artificial sea water circulation). industrial problem suggests that the smaller the loss of graphite matter is, the more relevant the couples of materials are. After the 6-h experiments, the couple graphite/TiC-reinforced Ti-6Al-4V is better than graphite/Ti-6Al-4V. The 50-h experiments lead to the opposite conclusion. This result confirms the limitations of short experiments. As a conclusion, the test duration should be chosen carefully in view of sound predictions for the industrial lifetime.

\subsection{Influence of the contact configuration}

For the purpose of comparison between two contact configurations (ring-on-disk, i.e., steady-state and permanent plan/plan contact, and pin-on-disk, i.e., periodic contact), experiments have been carried out with a pin-on-disk tribocorrosimeter [1]. The disk and the pin are, respectively, made of Ti-6Al-4V and of graphite. The pins are $10 \mathrm{~mm}$ diameter cylinders. Their surface of contact is plane with a chamfer of $1 \mathrm{~mm}$. The plane surface is polished; its roughness is approximately $0.1 \mu \mathrm{m}$. The average contact pressure between the two samples is $3 \mathrm{MPa}$ and the rotational speed is $40 \mathrm{rpm}$, which corresponds to a linear velocity of $0.015-0.052 \mathrm{~m} / \mathrm{s}$ across the friction track.

For the pin-on-disk experiments, a matter loss of the Ti-6Al-4V disk is observed for all studied electrochemical conditions, whereas for the ring-on-disk experiments, it is observed only with an anodic potential of $0.140 \mathrm{~V}$. Moreover, no corrosion product is found and the oxygen concentration is nearly homogeneous on the whole disk surface subjected or not to friction during pin-on-disk experiments which contrasts with that of the ring-on-disk experiments. This means that the degradations of the Ti-6Al-4V are different for these two configurations.

Nonetheless, for both set-ups (ring-on-disk or pin-on-disk), the most significant wear is the graphite wear. We observe transfer of graphite on the Ti-6Al-4V disk, in both cases. The experiments underline the influence of the contact. More precisely, the wear response of the both materials depends on the permanent contact regime (ring-on-disk experiment) or the periodic one (pin-on-disk experiment) between the samples. 


\section{Conclusion}

A new tribocorrosion experimental set-up has been developed to study materials wear for a ring in friction with a disk in seawater. The observations made at the end of the experiments allow us to determine the process of the loss of matter and of the damage of the ring and disk [11]. From the mechanical analysis of the contact conditions, the importance of the contact geometry is underlined and analyzed. The preferential matter loss on the edge of the friction zone is explained by the presence of high stresses in this part of the track. It is critical on the evolution of the contact conditions (distribution of the contact pressure), on the wear debris evacuation and on the evolution of the wear. Because of the electrochemical activity of both materials and of the geometry of the antagonists, the interpretation of the measured current is not direct. Consequently, it is necessary to use a specific electrochemical set-up to study the electrochemical conditions in the contact zone more accurately.

The influence of different parameters - such as the position of the materials in the structure, the applied load, the experiment time duration and the contact configuration - has been studied. The position of the materials in the ring-on-disk experiment changes quantitatively the graphite wear and the ejection of debris. The coupling of the electrochemical prescribed potential and the applied load on the wear has been focused on. It suggests further local analyses of the electrochemical conditions in the contact area including occlusive zones. The test duration appears to be crucial to evaluate a major parameter to estimate the wear law of the couple of materials because the cumulated loss of matter is nonlinear function of time.

\section{Acknowledgements}

The authors wish to thank Mr. Louchart of Centre technique d'Arcueil (France) for his technical assistance. They gratefully acknowledge the help provided by M. Keddam and M. Takenouti from the laboratory "Physique des Liquides et Electrochimie" (Paris VI University, France) about the electrochemical set-up with the current/potential converters and by P. Ponthiaux of
Ecole Centrale de Paris (France), for the pin-on-disk experiments.

\section{References}

[1] G. Lederer, Modélisation tribomécanique du frottement en milieu agressif, Doctoral thesis, Ecole Polytechnique, France, 1998.

[2] I. Serre, Contribution à l'étude des phénomènes d'usure par frottement en milieu marin, Doctoral thesis, Ecole Polytechnique, France, 2000.

[3] S. Mischler, P. Ponthiaux, A round robin on combined electrochemical and friction experiments on alumina/stainless steel contacts in sulfuric acid, Wear 248 (2001) 211-225.

[4] P. Jemmely, S. Mischler, D. Landolt, Tribocorrosion behaviour of the Fe-17Cr stainless steel in acid and alkaline solutions, Tribol. Int. 32 (1999) 295-303.

[5] M.F. Lizandier, E. Lanza, A. Sebaoum, A. Giroud, P. Guiraldenq, Characterization of porosity of ceramic coatings assigned to applications in sea water with the evolution of their electrochemical behaviour under friction, Wear 153 (1992) 387-397.

[6] J.M. Georges, Frottement, usure et lubrification, CNRS/Eyrolles, Paris, 2000.

[7] K. Kato, Wear in relation to friction-a review, Wear 241 (2000) 151-157.

[8] I. Serre, M. Bonnet, R.M. Pradeilles-Duval, Modeling an abrasive wear experiment by the boundary element method, Compte-Rendu à l'Académie des Sciences IIb 329 (2001) 803-808.

[9] A. Walter, W. Plitz, The ring-on-disk method: clinical significance of a wear-screening experiment of biomaterials for hip joint alloplasty, in: S.M. Perren, E. Schneider (Eds.), Biomechanics: Current Interdisciplinary Research, Martinus Nijoff, Dordrecht, 1985, pp. 129134.

[10] C. Deslouis, C. Gabrielli, B. Tribollet, Multi-channel potentiostatic control in electrochemistry: localized mass-transfer rates at the rotating disk electrode, Physicochem. Hydrodyn. 2 (1981) 23-30.

[11] I. Serre, N. Celati, R.M. Pradeilles Duval, Tribological and corrosion wear of graphite ring against $\mathrm{Ti}-6 \mathrm{Al}-4 \mathrm{~V}$ disk in artificial seawater, Wear 252 (2002) 711-718.

[12] Le Carbone-Lorraine society, Carbons and graphites for mechanical applications, Technical Notice for the use of graphite, 1999.

[13] M. Stemp, S. Mischler, D. Landolt, The effect of contact configuration on the tribocorrosion of stainless steel in reciprocating sliding under potentiostatic control, Corrosion Sci. 45 (2003) 625-640.

[14] D. Landolt, M. Stemp, S. Mischler, Electrochemical methods in tribocorrosion-a critical appraisal, Electrochim. Acta 46 (2001) 3913-3929. 